\title{
Live twin ectopic pregnancy with a high $\beta$ hCG value in a woman with a poor obstetric history.
}

\section{A case report}

\author{
L. N. Z. NENE, G. DREYER \\ Department of Obstetrics and Gynaecology, Pretoria Academic Hospital and University \\ of Pretoria, South Africa
}

\section{Introduction}

Twin ectopic pregnancy is rare, with about a hundred cases described worldwide (1) and an estimated incidence of 1 in 200 of all ectopic pregnancies (2). The incidence of live twin tubal pregnancy is reported as 1 in 125,000 pregnancies with only 8 reported cases of fetal cardiac activity $(1,3)$ found in the English literature. Quantitative $\beta$ hCG and ultrasound has revolutionised early diagnosis and outcome.

\section{Case report}

A 29 year old woman, gravida 4, para1, presented at the Pretoria Academic Hospital with an 8 week history of amenorrhoea, lower abdominal pain and vaginal bleeding for 2 weeks. She had a poor obstetric history, with a previous fresh stillborn baby at term (home birth) and 2 previous spontaneous first trimester miscarriages (at 8 weeks and 12 weeks). On examination she was haemodynamically stable with generalized tenderness, rebound and guarding over her lower abdomen. There was a palpable mass in the left iliac fossa. On vaginal examination, the cervix was closed with cervical excitation tenderness. The haemoglobin was $12,9 \mathrm{~g} / \mathrm{dl}$ and the quantitative $\beta \mathrm{hCG} 110744 \mathrm{mIU} / \mathrm{ml}$.

Transabdominal and transvaginal sonar revealed an empty uterus with an ectopic twin pregnancy on the left side. The crown rump lengths were $27,4 \mathrm{~mm}$ ( 9 weeks 4 days) and $37,3 \mathrm{~mm}$ (10 weeks 1 day) respectively with fetal cardiac activity present in both and a membrane separating the twins (Fig. 1, 2). There was free fluid in the pouch of Douglas (Fig. 3).

At laparotomy $800 \mathrm{ml}$ haemoperitoneum with a ruptured left tubal twin ectopic pregnancy in the ampulla was found (Fig. 4). A left salpingectomy was done and no post-operative complications occurred.

\section{Discussion}

Various authors have reported an association between recurrent spontaneous abortions and ectopic pregnancies, suggesting a common risk or etiological factor. The relative risk for ectopic pregnancy after recurrent early losses was found to be between 2.2 and $4.3(4,5)$. This is the first report of a twin ectopic associated with a poor obstetric history including early pregnancy losses. One previous case report in the literature reported a 
twin ectopic in a gravida 7, para 4 woman without describing her obstetric history. We could not find a known association between twinning and recurrent miscarriage.

The highest previously published $\beta$ hCG value in twin ectopic was $31672 \mathrm{mIU} / \mathrm{ml}$ (mean value $9846 \mathrm{mIU} / \mathrm{ml}$ ) in a 7 week pregnancy (Ansari). The highest gestational age reported in recent literature (with ultrasound diagnosis) was 11 weeks (Shivanand) however, the $\beta$ hCG value was not reported. The mean reported gestation is 8 weeks. As far as we could establish, our patient (at gestational age of 10 weeks) had the highest $\beta$ hCG level ever reported for twin ectopic pregnancy. Multiple pregnancies, live and advanced ectopic pregnancy are known to be associated with higher $\beta$ hCG values than expected.

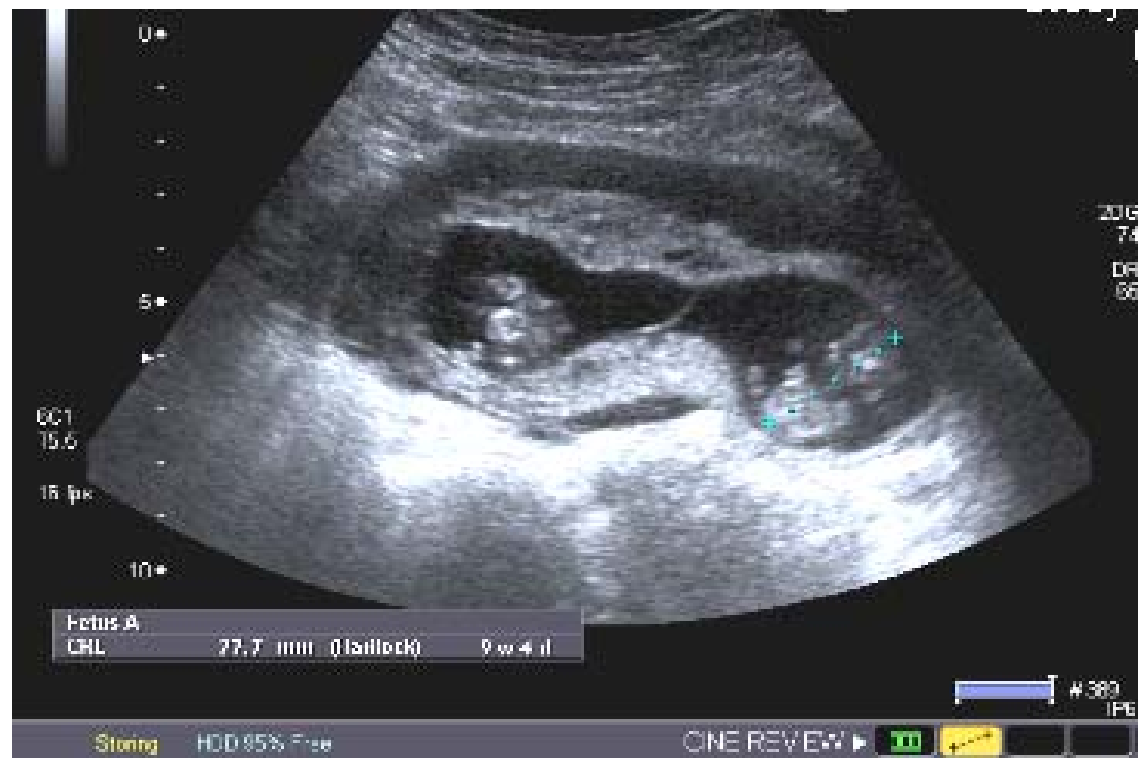

Figure 1. Transabdominal ultrasound image demonstrating CRL of twin 1 and membrane separating the sacs.

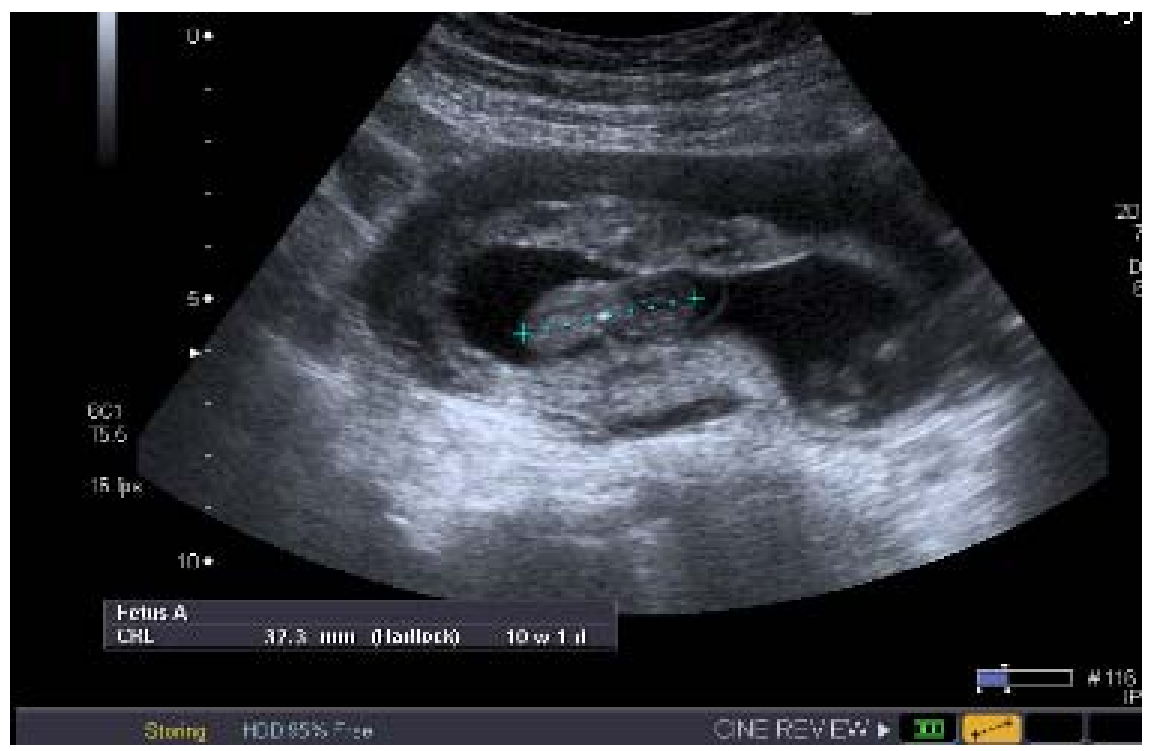

Figure 2. Transabdominal ultrasound image with CRL of twin 2. 


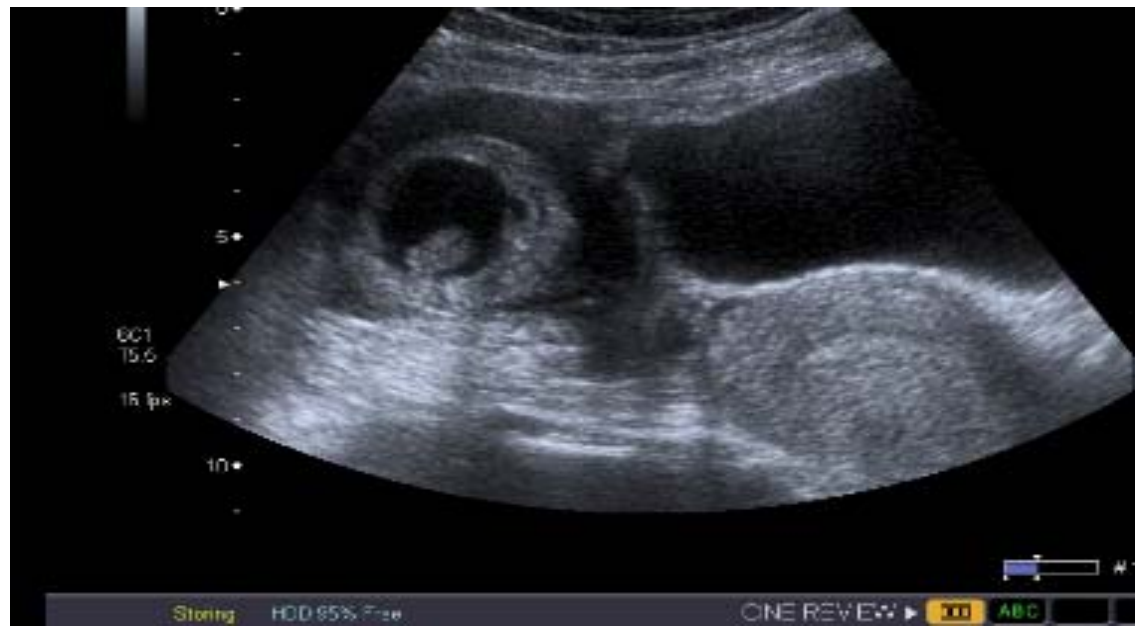

Figure 3. Transabdominal ultrasound image demonstrating empty uterus, free fluid and ectopic pregnancy.
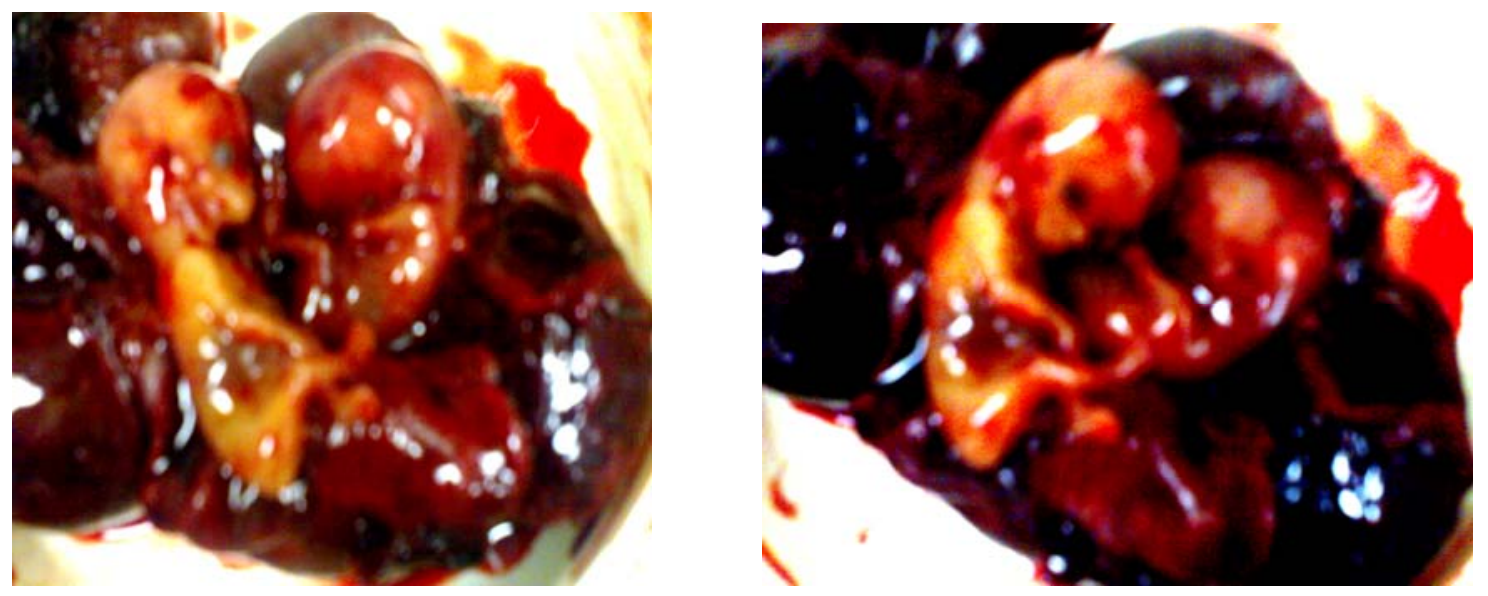

Figure 4. Twin fetuses found in ruptured left fallopian tube 


\section{$\underline{\text { References }}$}

1. Hois EL, Hibbeln J, Sclamberg J. Spontaneous twin tubal ectopic gestation. J Clin Ultrasound 2006; 34:352-355.

2. Hanchate V, Garg A, Sheth R, Rao J, Jadhav PJ, Karayil D. Transvaginal sonographic diagnosis of live monochorionic twin ectopic pregnancy. J Clin Ultrasound 2002;30:52-56.

3. Parker J, Hewson AD, Calder-Mason T, Lai J. Transvaginal ultrasound diagnosis of a live twin tubal ectopic pregnancy. Australas Radiol 1999;43:95-97.

4. Fedele L, Acaia B, Parazzini F, Ricciardiello O, Candiani GB. Ectopic pregnancy and recurrent spontaneous abortion: two associated reproductive failures. Obstet Gynecol 1989;73:206-208.

5. Coulam CB, Johnson PM, Ramsden GH, Wagenknecht DR, Faulk WP, et al. Occurrence of ectopic pregnancy among women with recurrent spontaneous abortion. Am J Reprod Immunol 1989; 21:105-107.

6. Ansari SM, Nessa L, Saha SK. Twin ectopic pregnancy 10 years after permanent sterilization. Australas Radiol 2000;44:107-108.

7. Shivanand G, Srivastana DN, Subramanian S. Transabdominal ultrasonography diagnosis of ectopic twin gestation. Europ J Radiol 2004;52:127-128. 